Justicia Juris, ISSN 1692-8571, Vol. 8. No 2. Julio-Diciembre 2012 Pág. 11-26

\title{
Actividades estructuradas / desestructuradas y delincuencia juvenil. Análisis de datos del ISRD-2
}

\section{Structured and unstructured activities and teenager crime. Data Analysis of ISRD-2}

\author{
MARCO GIORGI \\ Sociólogo, Magister en criminología y seguridad \\ Sociólogos asociados \\ marco.giorgi@hotmail.com
}

Recibido: Septiembre 15 de 2012

Aceptado: Noviembre 20 de 2012

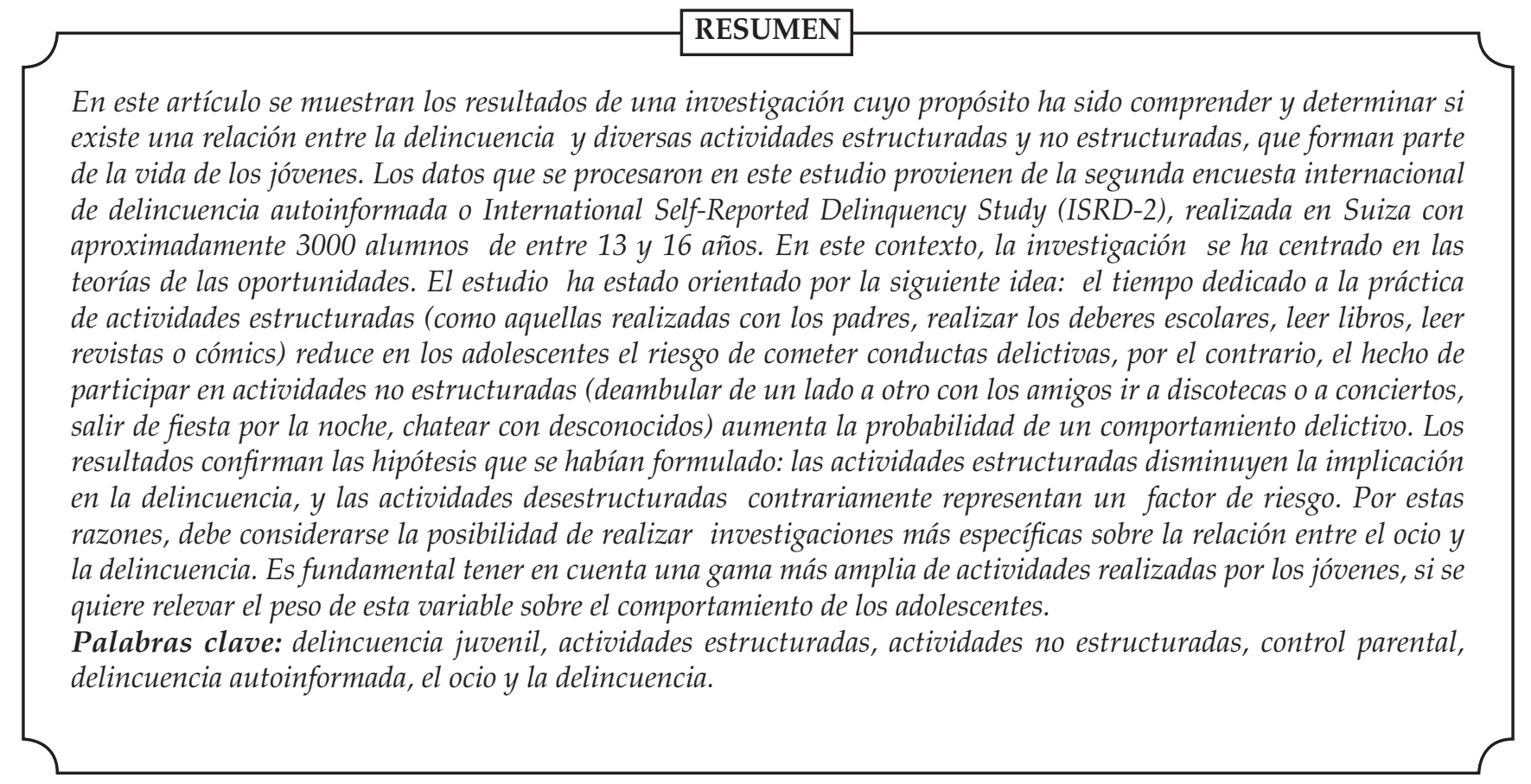

International Self-Reported Delinquency Study 2. 


\section{ABSTRACT}

The purpose of this study is to understand and determine whether there is a relationship between crime and various structured and unstructured activities that are part teenager's life. The collected data come from the second international survey of self-reported crime or Self-Reported Delinquency Study (ISRD-2), conducted in Switzerland with approximately 3,000 students between 13 and 16 years. In this context, research has been focused on theories of opportunities. It begins by considering that the time devoted to the practice of structured activities (activities with parents, doing homework, reading books, reading magazines or comics) reduces the risk of committing criminal acts, however, the act of participating in unstructured activities (hanging out with friends, going to clubs or concerts, partying at night, playing computer games or chatting with strangers) increases the likelihood of criminal behavior. The results confirm the hypothesis formulated: structured activities decreased involvement in crime, and unstructured activities contrary represent a risk factor. For these reasons, there must be more specific research carried out on the relationship between leisure and crime. It is essential to take into account a broader range of activities undertaken by young people to measure the weight of this variable on the behavior of adolescents in a closer look-

Key words: teenager criminal acts, structured activities, unstructured activities, parental control, self-reported delinquency, leisure and crime.

\section{Introducción}

El ocio se define como el tiempo libre del cual una persona puede disponer fuera de su ocupaciones habituales y las restricciones que estas le imponen (diccionario le petit Robert, 1993). Para el grupo de edad representado en el estudio, es decir, los jóvenes de 13 a 16 años, ese tiempo se refiere al dedicado a actividades diferentes a las actividades escolares. Larson y Verma (1999), en un estudio internacional sobre la gestión del tiempo libre de los jóvenes señalan que en los países occidentales una gran parte de ese tiempo los jóvenes lo dedica a ver la televisión o chatear con los amigos, pero también hay muchos jóvenes que se dedican a actividades estructuradas como hacer parte de una asociación cultural o deportiva. En general, estos autores encontraron que durante la adolescencia el tiempo pasado con los padres disminuye y el que se pasa con los amigos aumenta hasta ocupar una cuarta parte del tiempo libre del que dispone el joven o la joven. El conjunto de la vida social de los jóvenes está así principalmente relacionada con las actividades llevadas a cabo con los amigos y son precisamente estas actividades las que se analizaron en la presente investigación.

El tiempo libre puede ser considerado un arma de doble filo. Por un lado, en ausencia de supervisión, o de encuadramiento el adolescente dejado a sí mismo, corre un riesgo mayor de tener problemas de comportamiento incluida la delincuencia. De otro lado, si hay un esfuerzo conjunto para hacer que la recreación tenga un propósito constructivo para el individuo, el tiempo libre podría convertirse en un factor decisivo y favorecer el desarrollo en el adolescente de actitudes y valores compartidos por la sociedad civil.
El propósito de la investigación ha sido comprender y determinar si existe una relación entre la delincuencia y las diversas actividades, estructuradas y no estructuradas, que forma parte de la vida de los jóvenes. Los datos que se han analizados provienen de la segunda encuesta internacional de delincuencia autoinformada (ISRD 2 por sus siglas en inglés), realizada con aproximadamente 3000 alumnos suizos de edades comprendidas entre los 13 y 16 años. Conviene señalar que la encuesta ISRD -2, no estaba del todo centrada en el tema del tiempo libre, lo que significa que se tenía poca información acerca de este problema. Por esta razón, este estudio no puede considerarse como una investigación específica sobre el papel de las actividades de ocio o manejo del tiempo libre en la delincuencia, sino como un estudio exploratorio, que se realizó con el objetivo de sondear el terreno.

En el estudio primeramente, se ha observado la distribución estadística de las variables para tener una visión general de la muestra, seguidamente se construyeron variables referentes a las actividades estructuradas y las actividades no estructuradas. Posteriormente, mediante un análisis bivariado se examinó la correlación entre las variables y el comportamiento delictivo. Esto, con el fin de determinar la existencia de una relación estadística entre las variables en cuestión. En un segundo paso, se introdujo en este análisis las variables de control "edad" y "sexo" para ver si afectaban los resultados obtenidos. Por último, se construyó un modelo de regresión logística para identificar las variables que mejor explican el comportamiento desviado y delincuente.

En este artículo se hace referencia a algunos enfoques teóricos relativos al ocio, también se presentan las hipótesis 
y la metodología utilizada en la investigación. Por último, se presentan algunos de los resultados obtenidos y la discusión referente al impacto que tienen las actividades estructuradas y las no estructuradas de los adolescentes sobre el comportamiento delictivo de estos.

\section{Los enfoques teóricos}

\section{a. Las teorías de la socialización}

\section{i) La teoría de la asociación diferencial}

La teoría de la asociación diferencial, expuesta por Edwin H. Sutherland explica la conducta delictiva a través de la influencia de algunos hechos o eventos del pasado sobre la vida del delincuente (Sutherland, 1947/1966, p.87). Este enfoque en su versión final, se compone de nueve proposiciones, de las cuales tres son las más importantes pues las otras se pueden deducir (Opp 1974, citado por Killias, 2001). Sutherland explica que el comportamiento criminal se aprende (primera proposición) mediante un proceso de comunicación con otras personas (segunda proposición) y que este tipo de formación criminal se lleva a cabo mediante el aprendizaje de técnicas y actitudes criminales (octava proposición). Esto se hace a menudo en compañía de un grupo, donde los intercambios y las relaciones personales se supone son más bien íntimos. Es por ello, y de acuerdo con Sutherland que la pertenencia a un grupo delictivo constituye un factor determinante que influye en el grado de delincuencia del individuo, así como la duración, la intensidad y la frecuencia de contactos con modelos delincuentes refuerzan la tendencia al delito de la persona.

En esta perspectiva, las actividades recreativas, especialmente aquellas que se practican con el grupo de pares y sin supervisión, constituyen una fuente de peligro. Es en efecto, en tales circunstancias que el joven puede ser influenciado por los comportamientos delictivos del grupo de pares que él frecuenta, o puede llegar a conocer jóvenes delincuentes.

\section{ii) La teoría del aprendizaje social}

En los años que siguieron a la aparición de la teoría de Sutherland, muchos autores trataron de readaptar este enfoque con el fin de llenar los vacíos que la asociación diferencial presentaba ${ }^{1}$ La teoría más ampliamente aceptada en el campo de la criminología es la del aprendizaje social

\footnotetext{
Una de las lagunas más importantes ha sido señalada por Killias (2001), quien sostiene que la hipótesis subyacente a esta teoría no es verificable, porque Sutherland no especifica las variables causales que se suponen tienen un efecto sobre el comportamiento delincuente.
}

desarrollada por Burgess y Akers (1968) y teorizada posteriormente por Akers (1977). Este enfoque agrega al concepto de asociación diferencial otros elementos para explicar la conducta criminal. Según esta teoría, la probabilidad de que una persona se encamine hacia la delincuencia depende de la asociación con otros delincuentes (asociación diferencial), de los refuerzos/ castigos que la persona ha sufrido o que espera recibir como respuesta a su comportamiento (reforzamiento diferencial), de la exposición a modelos criminal/desviados (imitación) y de los valores favorable/desfavorable del individuo en relación con la noción de delito (definición).

El adolescente aprende estos conceptos en su entorno. Por tanto, es posible que el hecho de pasar tiempo realizando algunas actividades con sus padres pueda reforzar en el joven su conducta conforme a las normas, esto, gracias a la exposición a modelos y definiciones contrarios a la delincuencia. En cambio, ciertas actividades de ocio practicadas con su grupo de pares, sobre todo cuando éstas son poco estructuradas y/o sin supervisión de los adultos, ofrecen la oportunidad de estar expuestos a modelos criminales y a personas que valoran favorablemente la delincuencia. En tales situaciones, el comportamiento criminal del individuo se verá reforzado.

\section{b. La teoría del control social}

En 1969, Hirschi publicó la versión más conocida de la teoría del control social. Esta teoría trata de explicar la delincuencia juvenil en función de las relaciones o lazos entre el individuo y la sociedad. En esta perspectiva, Hirschi se desliga de otras teorías criminológicas, y en lugar de preguntarse por qué la gente toma el camino de la delincuencia, él se plantea la cuestión de por qué las personas respetan las normas y las convenciones sociales (Junger-Tas, 1988). Hirschi cree que la respuesta está en el control social implementado sobre el individuo. Este es un control que se ejerce por la existencia de normas y valores compartidos dentro de la comunidad, que deben acatarse con el fin de integrarse en la sociedad. Por lo tanto, la tendencia a la delincuencia estará pues influenciada por el «social bond», o vínculo social entre el individuo y la sociedad del cual Hirschi identifica cuatro dimensiones principales (Hirschi, 1969, p 16-34):

1. El apego del individuo a las personas que le son importantes (padres, amigos, profesores) constituye un freno, ya que los jóvenes, para no decepcionarlos prestara atención a cómo se comporta.

2. El apego actual o previsto en actividades convencionales (en la escuela, la iglesia, el trabajo) limita la tendencia a la delincuencia, pues el adolescente, con el fin de mantener el role que ha adquirido o de realizar sus sueños, evita tener una conducta desviada. 
3. La implicación en actividades convencionales (en la escuela, el club deportivo o cultural) tiene la ventaja de ocupar el tiempo y la energía del adolescente, en consecuencia reduce el número de posibilidades de tener un comportamiento desviado.

4. Las convicciones favorables a las normas existentes en la sociedad constituyen otro factor que impulsa al individuo a comportarse de acuerdo con lo establecido.

Las actividades recreativas tienen un impacto sobre cada una de estas dimensiones. Por ejemplo, las actividades llevadas a cabo con los padres (ir al cine, teatro, etc.) pueden fortalecer en el adolescente el apego a los padres. El hecho de realizar las tareas o deberes escolares le permite comprometerse e involucrarse en actividades convencionales, y más aún realizar deporte tiene el poder de fortalecer valores como la perseverancia, la cooperación o conformidad en el individuo.

\section{c. Las teorías de las ocasiones u oportunidades}

Las teorías tomadas en consideración precedentemente se focalizan todas en el individuo y las causas profundas que estimulan la tendencia a la delincuencia. Estas teorías ven la solución del problema en el cambio de las estructuras sociales (familia, grupo de amigos, escuela) que forman el carácter de la persona. La teoría de las oportunidades introduce un enfoque alternativo, que tiene en cuenta el papel desempeñado por la situación en el surgimiento de la propensión a la delincuencia.

La idea de delito como producto de la situación no es nueva ${ }^{2}$, pero no fue hasta la década de 1970 que las dos teorías principales de este enfoque surgen. El lifestyle model de Hindelang, Gottfredson y Garofalo (1978) relaciona el modo de vida con el riesgo de ser victimizado, y en este sentido, las personas más victimizadas son los hombres jóvenes, quienes pasando mucho tiempo fuera de la casa en las zonas sensibles de la ciudad y clubes nocturnos, tienen más oportunidades de encontrarse con delincuentes (Killias, 2001). En general, la routine activity approach de Cohen y Felson (1979) explica las variaciones en las tasas de criminalidad por los cambios en las actividades de rutina de las personas. El éxito de un acto criminal dependerá de la convergencia en el tiempo y en el espacio de tres componentes: un autor motivado, un objetivo atractivo y la ausencia de un guardián que lo proteja (Cohen y Felson, 1979, p. 604).

\footnotetext{
De hecho, ya en el siglo IV antes de Cristo. J.-C El filósofo griego Aristóteles propuso una conceptualización de los factores situacionales muy similar a la contenida en las teorías contemporáneas (Killias, 2001, cap. 7).
}

Osgood et al. (1996) extienden esta teoría a las actividades de ocio. En esta perspectiva, algunas de las actividades practicadas con los pares o compañeros, especialmente las que se desarrollan sin supervisión ni estructura (andar por las calles, ir a discotecas o conciertos nocturnos), son susceptibles de reforzar la tendencia al comportamiento criminal, y esto incluso en los casos en que el propósito en sí mismo de la actividad no es desviado.

\section{d. La teoría de la acción situacional}

Una visión alternativa en la explicación de la criminalidad es proporcionada por la teoría de la acción situacional de Wikström (2004), quien integra dentro del mismo marco teórico el enfoque individual y del entorno. Esta teoría considera que el comportamiento criminal es el resultado de la interacción entre la tendencia a la delincuencia de la persona y las características del contexto ambiental. A nivel individual, la tendencia a la delincuencia está determinada por la moralidad (valores y emociones) del individuo, lo que influye la percepción de la delincuencia como acción alternativa, así como su capacidad para ejercer el autocontrol, lo cual tiene un efecto sobre la capacidad de resistirse a la tentación de cometer actos delictivos. En el ámbito del entorno, el factor decisivo está representado por el contexto moral de la situación, que influye en el comportamiento del individuo, proporcionándole diversos motivaciones y tentaciones (Wikström y Svensson, 2008).

Desde este punto de vista, el tiempo que pasa el joven adolescente con su grupo de pares realizando actividades no estructuradas constituye el contexto que genera el mayor riesgo (Agnew y Petersen, 1989;. Osgood et al 1996), pero este elemento no es en sí mismo suficiente para que la conducta criminal surja. En efecto, de acuerdo con la teoría de la acción situacional, la exposición a un medio ambiente criminógeno influye en la implicación en conductas delictivas solamente entre los jóvenes que tienen ya una tendencia a la delincuencia.

\section{El rol del grupo de pares}

Como ya se ha dicho, la adolescencia es un período en el cual el tiempo que se comparte con los amigos aumenta gradualmente, y por lo tanto estos se convierten en los principales agentes de socialización en esta edad. En un trabajo de investigación que busca establecer el vínculo entre la delincuencia juvenil y el manejo del tiempo libre de los adolescentes, parece esencial discutir específicamente el papel del grupo de pares o los amigos señalados en las teorías y estudios comentados anteriormente.

Las teorías de la socialización suponen la existencia de un vínculo de causalidad entre la asociación con amigos 
delincuentes y la delincuencia de la persona, pero esta idea ha sido objeto de numerosas críticas desde su aparición. De hecho, varios autores (Glueck y Glueck, 1950, citado por Killias, 2001) afirman que el orden temporal de esta relación podría ser inverso en el sentido de que sería el estilo de vida desviado lo que llevaría al individuo a buscar la compañía de otros delincuentes haciendo más fácil la asociación con un grupo criminal. Más recientemente, una serie de investigaciones longitudinales (Junger-Tas, 1988; Elliott y Menard, 1996) encontró un proceso de influencia mutua entre los dos fenómenos, donde la delincuencia es tanto el producto como la causa de la pertenencia a un grupo de delincuentes. Este descubrimiento, así como otras consideraciones a nivel de la metodología utilizada en los estudios realizados en el pasado ${ }^{3}$, sugieren que durante mucho tiempo la importancia de los amigos delincuentes en este proceso se ha sobreestimado.

La teoría del control social considera en cambio a los amigos -que respeten o no las normas- como un factor protector de la delincuencia. Efectivamente, según Hirschi, el apego a los amigos, como también el apego a otras figuras importantes en la vida de un adolescente (padres, maestros), fortalece los vínculos sociales y la integración en la sociedad. En este sentido, más el adolescente se relaciona con su grupo de pares, menos tenderá a desviarse. Esta relación no ha sido apoyada por la comunidad científica. De hecho, numerosos estudios (Hindelang, 1973; Elliott \& Voss, 1974) no se identifican con las predicciones de Hirschi y más bien consideran las características del grupo de pares del adolescente como factores importantes para comprender la influencia de estos sobre aquel.

En cuanto a las teorías de las oportunidades, plantea que el tiempo que el adolescente pasa con su grupo de pares, que ellos sean desviados o no, aumenta la probabilidad de caer en la delincuencia, pero esto se debe principalmente al hecho de que las actividades de ocio que realiza con los amigos son a menudo de tipo no estructurada y/o sin supervisión. En este sentido, la presencia de los pares o amigos facilita la participación en la delincuencia, pero el factor clave es el grado de estructuración de la actividad que realiza el adolescente.

La teoría de la acción situacional introduce así un elemento de la individualidad, en el sentido de que un

\footnotetext{
Se hace referencia específicamente al papel jugado por la proyección en el análisis de las tasas de criminalidad del grupo de pares. Efectivamente, en el pasado, el comportamiento de los amigos era evaluado pidiéndole a los adolescentes de describir ellos mismos los hábitos de aquellos, lo que implica una tendencia al sesgo. Por lo tanto, habría sido necesario interrogar directamente a los amigos en cuestión para conocer más objetivamente sus hábitos.
}

estilo de vida riesgoso (actividades no estructuradas, amigos delincuentes) aumenta su impacto sobre la delincuencia cuando interactúa con una tendencia a la delincuencia en la persona en cuestión (débil moralidad y autocontrol). En esta teoría, la influencia del grupo de pares sobre la delincuencia está entonces condicionada por esta tendencia ${ }^{4}$, y si ella es débil, la influencia de los pares delincuentes será reducida.

\section{Metodología}

\section{a. Hipótesis}

La investigación tuvo como objetivo poner a prueba las siguientes hipótesis:

1. El tiempo dedicado a practicar actividades estructuradas reduce el riesgo de adoptar un comportamiento delictivo.

2. El tiempo dedicado a practicar actividades no estructuradas aumenta la probabilidad de caer en la delincuencia.

\section{b. Las encuestas de delincuencia autoinformada y el ISRD}

En las encuestas de delincuencia autoinformada se les pide a las personas, por lo general jóvenes ${ }^{5}$, responder a preguntas sobre su estilo de vida, sus actitudes acerca de diversos temas (familia, escuela, amigos) y su comportamiento delincuente. Preguntas que tienen en cuenta factores sociodemográficos también son incluidas (Aebi, 2009). El objetivo es tener tanta información como sea posible sobre las variables que están relacionadas con la delincuencia.

\section{c. Muestra}

Los datos analizados en la investigación hacen parte del estudio nacional suizo realizado en el marco del ISRD-2 (encuesta internacional de delincuencia autoinformada2) Este estudio se ha realizado con más de 3000 jóvenes escolares en Suiza, de $7^{\circ}, 8^{\circ}$ y $9^{\circ}$ grado, la mayoría en edades de entre 13 a 16 años. La encuesta proporciona información sobre el contexto de vida de los jóvenes e in-

4 Todavía se puede suponer la existencia de un proceso inverso. En efecto, el hecho de pasar mucho tiempo con sus amigos delincuentes puede cambiar algunos de los valores de la persona y reducir el nivel de auto-control. En tales circunstancias, un estilo de vida riesgoso podría reforzar la tendencia a la delincuencia en los adolescentes.

5 En efecto, las encuestas de delincuencia auto informada han demostrado su eficacia sobre todo entre los adolescentes, quienes, a diferencia de los adultos, confiesan más fácilmente los delitos cometidos (Aebi, 2006). 
cluye variables demográficas y sociales. Los estudiantes fueron motivados a proporcionar información sobre los delitos que puedan haber cometido (vandalismo, uso y venta de drogas, delitos violentos, etc.) Y sobre conductas desviadas que pudieran tener (ausentismo escolar, consumo de alcohol, etc.) Por último, se abordan también cuestiones sobre actos de intimidación (extorsión, acoso, robo, etc.). En la muestra nacional suiza, que fue la base de esta investigación, 20 cantones fueron encuestados en las tres regiones lingüísticas (Suiza alemana, Suiza francesa y Suiza italiana). En total, 3.617 cuestionarios debidamente diligenciados por las 207 clases sondeadas fueron recogidos en las 70 escuelas que participaron en la encuesta, en razón de tres clases por escuela $\left(7^{\circ}, 8^{\circ}\right.$ y $\left.9^{\circ}\right)$. El método utilizado fue la entrevista en línea: $\mathrm{CAWI}^{6}$.

\section{d. Variables y operacionalización}

Se han dividido las variables en tres grupos. Las variables independientes, constituidas por las actividades estructuradas y no estructuradas, las variables dependientes, que corresponden a las conductas desviadas y delictivas, y por último, las variables de control, que incluyen las variables relativas a las características individuales y a las teorías de la socialización y del control social.

\section{Variables Independientes}

En cuanto a la elección de las actividades a introducir en el análisis, el estudio se ha interesado en las variables que mejor representan, por un lado, las actividades estructuradas y de otra parte las no estructuradas. Por esta razón, se ha eliminado algunos ítems / elementos («hacer deporte», «tocar un instrumento») para las que había preguntas demasiado vagas que no permitían determinar si las actividades en cuestión eran estructuradas o no estructuradas.

En cuanto a las actividades estructuradas, se eligieron las variables «hacer sus deberes o tareas», «leer libros» y «leer revistas o cómics.» Para estos ítems se les pidió a los adolescentes que indicaran de la lista el número de horas diarias dedicadas a tal actividad. Por último, se introdujó la variable «realizar actividades con sus padres», preguntándole el número de veces por semana que el adolescente realizaba una actividad recreativas (asistir a eventos deportivos, ir al cine, etc.) con sus padres.

En cuanto a las actividades no estructuradas, se eligieron las variables «salir por la noche»y «andar de un lado a otro con los amigos», para las cuales se les preguntó por el número de veces por semana y el número de horas dedicadas a esa actividad. Por último, las variables «ir dis-

Computer-Assisted Web Interview/Entretien assisté par ordinateur. cotecas o conciertos» y «jugar juegos de computadora / chatear» también fueron introducidas. En estos dos últimos casos, se les pidió que indicaran la frecuencia de las actividades recreativas practicadas con sus compañeros.

Otras cuestiones relacionadas con las actividades llevadas a cabo también con sus compañeros, no se tomaron en consideración porque contenían sesgos intrínsecos. Este es el caso de las variables que hacen referencia a un comportamiento desviado (vandalismo, hurtos, acoso, consumo de drogas), para las cuales la explicación de su relación con la delincuencia estaba basada principalmente en una tautología.

Desafortunadamente, no se pudo identificar las actividades estructuradas realizadas con los amigos. Por esta razón, las actividades estructuradas corresponden de manera general a las recreaciones realizadas solo o con sus padres y las actividades no estructuradas son principalmente las que se practican con sus compañeros o amigos.

\section{Variables Dependientes}

Los comportamientos tomados en cuenta fueron agrupados en dos categorías: el uso de sustancias y la comisión de los actos delictivos. La clasificación de estos comportamientos sigue la que se aplicó en el estudio Killias et al. (2009).

En cuanto a las sustancias psicoactivas, las preguntas tuvieron en cuenta el consumo de alcohol (cerveza, vino y licores) y las drogas blandas (marihuana y hachís). En cuanto a estas variables, la prevalencia vida y la prevalencia durante las últimas cuatro semanas (a la fecha de aplicación del instrumento) fueron medidas.

En lo referente a la comisión de actos criminales, en el estudio se agruparon esos comportamientos en delitos violentos frecuentes (peleas en grupo y porte de arma), delitos violentos raros (raponazo, hurto y daños corporales), el vandalismo, hurtos, delitos contra la propiedad (robo de apartamento, robo de vehículos, robo dentro de un vehículo, robo de bicicleta, o de velomotor) y venta de drogas. Para estas variables, la prevalencia de vida y la prevalencia durante los últimos doce meses (con relación a la fecha de aplicación del instrumento) han sido medidas.

\section{Variables de control}

La investigación se interesó en las variables relacionadas con las características individuales (edad y sexo de los adolescentes), así como la variable «supervisión de los padres», medida con la ayuda de dos preguntas mediante las cuales se indago a los niños si sus padres sabían en general, donde se encontraban cuando ellos estaban fuera de la casa y si además les imponían una hora de llegada. 


\section{e. Método de Análisis}

En la investigación en primer lugar, se ha observado la distribución estadística de las variables para tener una visión general de la muestra, seguidamente se construyeron dos variables contextuales, globalizando la una las actividades estructuradas y la otra las actividades no estructuradas. Posteriormente, se utilizaron estas nuevas variables para realizar análisis bivariado, utilizando tablas de contingencia, con el fin de examinar la correlación entre las variables y el comportamiento delictivo. Esto, con el fin de determinar la existencia de una relación estadística entre las variables en cuestión, lo cual se hizo con la prueba de Chi2 o test de independencia $\left(\chi^{2}\right)^{7}$ En un segundo paso, se introdujo en este análisis las variables de control «edad»y «sexo» para ver si afectaban los resultados obtenidos. Por último, se construyó un modelo de regresión logística para identificar las variables que mejor explican el comportamiento desviado y delincuente.

\section{Algunos resultados obtenidos}

\section{a. Análisis descriptivo}

\section{i) Distribución de las variables independientes}

En primer lugar, se determinó la frecuencia de las actividades de ocio o recreación estudiadas, a continuación, se volvió a codificar cada una de las variables independientes en tres categorías, y esto de acuerdo con las indicaciones suministrada por la distribución de frecuencias. En general, la primera categoría incluyó a los jóvenes que realizan poco o nunca una determinada actividad, en cuanto a la segunda ella representa los que consagran un tiempo mediano, y finalmente, en la última categoría se encuentran aquellos que pasan mucho tiempo practicando dicha actividad.

En cuanto a las actividades estructuradas, la tabla 1 permite observar que la lectura no es la preferencia de muchos adolescentes. De hecho, el 44,1\% de ellos dicen que nunca lee libros, y el 41\% manifestó que no leen revistas o cómics. En contraste, los adolescentes que a menudo leen, es decir, una hora o más por día, representan respectivamente $23,1 \%$ y $16,4 \%$. En lo referente a los deberes, la tendencia es similar, se encontró una mayoría simple de los encuestados $(44,7 \%)$ que reportaron emplear sólo treinta minutos al día o menos en la realización de tareas y una minoría $(16,6 \%)$ que afirmó consagrar dos horas o más. Por último, las actividades con los padres también se practican poco, ya que sólo el 20,1\% de los adolescentes realizan estas actividades más de una vez a la semana.

Tabla 1. Distribución estadística de actividades estructuradas

\begin{tabular}{|l|l|c|}
\hline \multicolumn{1}{|c|}{ Variables } & \multicolumn{1}{|c|}{ Categorías } & \multicolumn{1}{c|}{ Porcentaje } \\
\hline \multirow{4}{*}{ Actividades con los padres $(\mathrm{N}=3629)$} & 1 al menos una vez al mes & $38.5 \%(1398)$ \\
\cline { 2 - 3 } & 1 vez par semana & $41.4 \%(1502)$ \\
\cline { 2 - 3 } & más de una vez por semana & $20.1 \%(729)$ \\
\hline \multirow{4}{*}{ Hacer las tareas (N=3619) } & al menos 30 minutos diarios & $44.7 \%(1616)$ \\
\cline { 2 - 3 } & 1 hora diaria & $38.8 \%(1402)$ \\
\cline { 2 - 3 } & 2 horas diarias o más & $16.6 \%(600)$ \\
\hline \multirow{3}{*}{ Leer libros $(\mathrm{N}=3595)$} & Nunca & $44.1 \%(1585)$ \\
\cline { 2 - 3 } $\begin{array}{l}\text { Leer revistas o cómics } \\
(\mathrm{N}=3600)\end{array}$ & 30 minutos diarios & $32.8 \%(1179)$ \\
\cline { 2 - 3 } & 1 hora diaria o más & $23.1 \%(832)$ \\
\hline & Jamais & $42.6 \%(1533)$ \\
\cline { 2 - 3 } & 30 minutos diarios & $16.4 \%(590)$ \\
\cline { 2 - 3 } & 1 hora diaria o más & $(1477)$ \\
\hline
\end{tabular}

7 Se ha establecido el nivel de significación a 5\%, valor establecido por convención por los estadísticos, lo que implica que el resultado se considera significativo si tiene menos del $5 \%$ de probabilidad (pvalor calculado $f 0.05$ ) de ser obtenido por casualidad 
Tabla 2. Distribución estadística de las actividades no estructuradas

\begin{tabular}{|l|l|c|}
\hline \multicolumn{1}{|c|}{ Variables } & \multicolumn{2}{|c|}{ Categorías } \\
\hline \multirow{3}{*}{ Salir por las noches $(\mathrm{N}=3559)$} & Nunca & $18.5 \%(660)$ \\
\cline { 2 - 3 } & 1 o 2 veces par semana & $49.0 \%(1743)$ \\
\cline { 2 - 3 } & 3 veces par semana o mas & $32.5 \%(1157)$ \\
\hline \multirow{2}{*}{$\begin{array}{l}\text { Andar de un lado a otro con los amigos } \\
(\mathrm{N}=3563)\end{array}$} & 1 hora diaria al menos & $35.4 \%(1262)$ \\
\cline { 2 - 3 } & 2 o 3 hora diaria & $38.4 \%(1367)$ \\
\cline { 2 - 3 } & 4 hora diaria o mas & $26.2 \%(935)$ \\
\hline \multirow{3}{*}{ Ir a discotecas o conciertos $(\mathrm{N}=3598)$} & Nunca & $49.2 \%(1770)$ \\
\cline { 2 - 3 } & A veces & $39.1 \%(1407)$ \\
\cline { 2 - 3 } & A menudo / siempre & $11.7 \%(421)$ \\
\hline \multirow{3}{*}{ Jugar/chatear en el computador $(\mathrm{N}=3607)$} & Nunca & $17.2 \%(621)$ \\
\cline { 2 - 3 } & A veces & $43.1 \%(1409)$ \\
\cline { 2 - 3 } & A menudo / siempre & \\
\hline
\end{tabular}

La Tabla 2 muestra que las actividades no estructuradas son al contrario muy común entre los adolescentes. Por ejemplo, poco de entre ellos no salen nunca (18,5\%), mientras que la mayoría salen una vez o dos veces por semana $(49 \%)$ o más $(32,5 \%)$. El tiempo dedicado a andar de un lado a otro con los amigos es también muy largo, de hecho, el 38,4\% de los jóvenes pasar 2 o 3 horas por día en compañía de sus compañeros y el $26,2 \%$ dijo que incluso pasan 4 horas o más cada día. Con respecto al hecho de jugar o chatear en el computador, se observa la misma tendencia, ya que sólo el 17,2\% de los jóvenes dicen que nunca practican estas actividades, mientras que la mayoría respondió "a veces" $(39,1 \%)$ o "a menudo/siempre" $(42,7 \%)$. En cuanto al hecho de ir a discotecas o a conciertos los resultados resultan un poco dudosos, ya que casi la mitad $(49,2 \%)$ de los encuestados nunca lo hace, mientras que sólo el 11,7\% de los adolescentes lo hacen a menudo o siempre.
En general, se constata que la distribución entre las actividades estructuradas y no estructuradas, es bastante heterogénea, probablemente porque las primeros se consideran obligaciones (hacer los deberes, practicar actividades con los padres) o como actividades que requieren un cierto nivel de concentración y esfuerzo (leer libros, revistas o cómics). Por el contrario, las actividades no estructuradas permiten a los jóvenes a mantenerse en contacto con sus compañeros y divertirse, lo que parece explicar más fácilmente el hecho de que estas actividades sean más frecuentes, aunque algunos resultados pueden plantear dudas. La única excepción en este caso está representada por la variable ligada a las salidas a discotecas o a conciertos, para la cual solamente una pequeña parte de los adolescentes es concernida. Este otro resultado probablemente se explica en función de la edad de los adolescentes interrogados que no han alcanzado todavía la edad permitida no pueden todavía asistir a clubes nocturnos.

\section{i) Distribución de las variables dependientes}

Tabla 3. Distribución estadística para las variables dependientes

\begin{tabular}{|l|c|c|c|c|}
\hline \multirow{2}{*}{ Variables } & \multicolumn{2}{c|}{ Prevalencia vida } & \multicolumn{2}{c|}{${\text { Prevalencia 12 } \text { meses }^{8}}^{\mathbf{2}}$} \\
\cline { 2 - 5 } & Si & Total & Si & Total \\
\hline Delitos violentos frecuentes & $21 \%(761)$ & $(\mathrm{N}=3618)$ & $13.1 \%(475)$ & $(\mathrm{N}=3615)$ \\
\hline Delitos violentos raros & $5.5 \%(197)$ & $(\mathrm{N}=3619)$ & $2.6 \%(95)$ & $(\mathrm{N}=3619)$ \\
\hline Vandalismo & $13.4 \%(484)$ & $(\mathrm{N}=3601)$ & $7.8 \%(279)$ & $(\mathrm{N}=3592)$ \\
\hline Hurto & $23.6 \%(853)$ & $(\mathrm{N}=3614)$ & $9.1 \%(329)$ & $(\mathrm{N}=3599)$ \\
\hline Delitos contra la propiedad raros & $8.9 \%(323)$ & $(\mathrm{N}=3625)$ & $4.8 \%(174)$ & $(\mathrm{N}=3625)$ \\
\hline Venta de drogas & $3.7 \%(131)$ & $(\mathrm{N}=3591)$ & $2.8 \%(99)$ & $(\mathrm{N}=3585)$ \\
\hline Alcohol & $68.2 \%(2474)$ & $(\mathrm{N}=3626)$ & $39.1 \%(1417)$ & $(\mathrm{N}=3621)$ \\
\hline Haschich & $17.5 \%(630)$ & $(\mathrm{N}=3593)$ & $7.2 \%(259)$ & $(\mathrm{N}=3589)$ \\
\hline
\end{tabular}

8 Prevalencia 4 semanas para el consumo de alcohol y hachis. 
En cuanto a la distribución de la conducta delictiva, se observa que sólo una minoría de los adolescentes está involucrada en ella. Los comportamientos más comunes están representados por los frecuentes actos violentos (riñas o peleas colectiva y porte de arma), con la participación del $21 \%$ de los adolescentes por la tasa de la prevalencia de vida y el $13,1 \%$ por la tasa de la prevalencia de los últimos doce meses por el hurto, que ha sido cometido por $23,6 \%$ de los jóvenes en el curso de su vida y por un 9,1\% en el curso del año anterior, y el vandalismo, del cual $13.4 \%$ de los jóvenes admitió haberlo cometido por lo menos una vez en la vida, y el 7,8\% durante los últimos doce meses. Por el contrario la venta de drogas, los delitos violentos $\operatorname{raros}^{9}$ y los delitos contra la propiedad ${ }^{10}$ se sitúan por debajo del $10 \%$ de prevalencia de vida y el $5 \%$ para la prevalencia de doce meses. El alcohol (alcopops, cerveza, vino y licores) es claramente la sustancia más frecuente, más de dos tercios de los jóvenes $(68,2 \%)$ reconocen haberlo consumido en su vida y un $39,1 \%$ en el curso del último mes (previo o anterior a la encuesta). La tasa de consumo de hachís es más baja ella representa 17,5\% de los adolescentes por la prevalencia de vida y el $7,2 \%$ en la prevalencia de las últimas cuatro semanas (previo o anterior a la encuesta).

En general, se encontró que para las variables dependientes no hubo diferencia significativa entre la prevalencia de vida y la de los últimos doce meses (o el mes pasado en el caso del uso de sustancias). Lucia et al. (2006) explican estos resultados diciendo que si se tiene en cuenta la edad de los adolescentes encuestados, está claro que los delitos se cometieron en el pasado reciente.

\section{iii) La distribución de las variables de control}

Tabla 4. Distribución estadística de las variables de control

\begin{tabular}{|l|l|l|}
\hline \multicolumn{1}{|c|}{ Variables } & \multicolumn{2}{c|}{ Categorías } \\
\hline \multirow{2}{*}{ Sexo $(\mathrm{N}=3628)$} & mujer & $50.1 \%(1817)$ \\
\cline { 2 - 3 } & hombre & $49.9 \%(1811)$ \\
\hline \multirow{2}{*}{ Edad (N=3631) } & $12-14$ años & $54.8 \%(1989)$ \\
\cline { 2 - 3 } & $15-17$ años & $45.2 \%(1642)$ \\
\hline $\begin{array}{l}\text { Supervisión } \\
\text { parental }(\mathrm{N}=3213)\end{array}$ & fuerte & $83.7 \%(2689)$ \\
\cline { 2 - 3 } & débil & $16.3 \%(524)$ \\
\hline
\end{tabular}

Hurto a personas con violencia, raponazo y lesiones corporales.

10 Robo de apartamentos, robo de vehículo, robo dentro de un vehículo, robo de bicicletas o de velomotor.
En la muestra se encuentra casi la misma proporción de mujeres $(50,1 \%)$ y de varones $(49,9 \%)$. Más de la mitad de los jóvenes $(54,8 \%)$ tienen entre 12 y 14 años, los otros $(45,2 \%)$ con edades entre 15 y 17 años. La supervisión de los padres es fuerte en el $83,7 \%$ de los encuestados y es débil en el 16,3\% de ellos.

\section{b. Análisis bivariado}

\section{i) Las actividades estructuradas}

La variable "actividades estructuradas" se ha construido a partir de las variables independientes "actividades con los padres","hacer los deberes" ,"leer libros", "leer revistas o cómics". Esta variable ha sido recodificada en tres categorías: los jóvenes que pasan poco tiempo practicando actividades estructuradas, los que gastan un tiempo medio y finalmente los que practican actividades con frecuencia esas actividades.

La tabla 5 permite observar que los valores de $\mathbf{p}$ son todos de .000 y las relaciones son pues todas significativas. Entonces, en regla general, más el joven practica actividades estructuradas, menos él está implicado en conducta delictiva. Por ejemplo, el 11,7\% de los jóvenes que pasan poco tiempo en actividades estructuradas ya han cometido actos de vandalismo, contra el 5,2\% de las personas que pasan un tiempo promedio y el $4,5 \%$ de los que pasan mucho tiempo.

\section{ii) Las actividades no estructuradas}

La variable "Actividades no estructuradas" se ha construido a partir de las variables independientes "vida nocturna", "ir de un lado a otro con los amigos", "ir a discoteca o a un concierto "," chatear o jugar en la computadora". Esta variable ha sido recodificada en tres categorías: los jóvenes que pasan poco tiempo practicando actividades estructuradas, los que gastan un tiempo medio y finalmente los que practican estas actividades a menudo.

La Tabla 6 muestra que las relaciones son una vez más todas significativas, con un p-valor de .000 para todos los cruces. El tiempo dedicado a practicar actividades no estructuradas se correlaciona positivamente con la conducta delictiva, de forma que más un joven se involucra en estas actividades, más se involucra en comportamientos delictivos. Por ejemplo, sólo el 1,2\% de los jóvenes que realizan poca de actividades no estructuradas consumen hachís, contra el 5,5\% y el 12,7\% de los que pasan un tiempo medio y/o alto en esas actividades. 
Tabla 5. Relación entre delincuencia (prevalencia de 12 meses o 4 semanas) y tiempo pasado a practicar actividades estructuradas

\begin{tabular}{|l|c|c|c|c|c|}
\hline \multirow{2}{*}{ Delitos } & \multicolumn{3}{c|}{ Actividades estructuradas } & \multicolumn{2}{c|}{} \\
\cline { 2 - 6 } & \multicolumn{1}{|c|}{ Poco } & suficiente & mucho & Sig. & N \\
\hline Delitos violentos frecuentes & $18.7 \%(266 / 1422)$ & $10.2 \%(136 / 1336)$ & $7.5 \%(59 / 785)$ & .000 & 3543 \\
\hline Delitos violentos raros & $3.8 \%(54 / 1426)$ & $1.7 \%(23 / 1336)$ & $1.1 \%(9 / 785)$ & .000 & 3547 \\
\hline Vandalismo & $11.7 \%(166 / 1418)$ & $5.2 \%(69 / 1326)$ & $4.5 \%(35 / 781)$ & .000 & 3525 \\
\hline Hurto & $12.6 \%(179 / 1417)$ & $8.0 \%(107 / 1332)$ & $4.9 \%(38 / 782)$ & .000 & 3531 \\
\hline Delitos contra la propiedad & $7.7 \%(110 / 1430)$ & $3.7 \%(50 / 1338)$ & $1.0 \%(8 / 785)$ & .000 & 3553 \\
\hline Venta de drogas & $5.2 \%(73 / 1408)$ & $1.6 \%(21 / 1323)$ & $0.6 \%(5 / 783)$ & .000 & 3514 \\
\hline Alcohol & $51.9 \%(742 / 1430)$ & $34.6 \%(463 / 1339)$ & $23.2 \%(182 / 783)$ & .000 & 3552 \\
\hline Hachís & $11.8 \%(167 / 1416)$ & $5.3 \%(70 / 1327)$ & $2.2 \%(17 / 776)$ & .000 & 3519 \\
\hline
\end{tabular}

Tabla 6. Relación entre la delincuencia (prev.12 mes o 4 semanas) y el tiempo empleado en actividades no estructuradas.

\begin{tabular}{|l|c|c|c|c|c|}
\hline \multirow{2}{*}{ Delitos } & \multicolumn{3}{|c|}{ Actividades no estructuradas } & \multicolumn{2}{c|}{} \\
\cline { 2 - 6 } & poco & suficiente & mucho & Sig. & N \\
\hline Delitos violentos frecuentes & $5.8 \%(44 / 759)$ & $11.7 \%(157 / 1343)$ & $19.0 \%(252 / 1324)$ & .000 & 3426 \\
\hline Delitos violentos raros & $1.2 \%(9 / 759)$ & $1.3 \%(18 / 1345)$ & $4.8 \%(63 / 1325)$ & .000 & 3429 \\
\hline Vandalismo & $2.0 \%(15 / 750)$ & $5.8 \%(77 / 1338)$ & $13.0 \%(171 / 1319)$ & .000 & 3407 \\
\hline Hurto & $4.1 \%(31 / 757)$ & $7.9 \%(106 / 1335)$ & $13.3 \%(175 / 1318)$ & .000 & 3410 \\
\hline Delitos contra la propiedad & $0.9 \%(7 / 759)$ & $3.6 \%(48 / 1347)$ & $8.3 \%(110 / 1330)$ & .000 & 3436 \\
\hline Venta de drogas & $0.5 \%(4 / 756)$ & $2.2 \%(30 / 1338)$ & $4.7 \%(62 / 1307)$ & .000 & 3401 \\
\hline Alcohol & $19.7 \%(149 / 757)$ & $38.5 \%(518 / 1344)$ & $52.6 \%(700 / 1330)$ & .000 & 3431 \\
\hline Haschich & $1.2 \%(9 / 751)$ & $5.5 \%(73 / 1337)$ & $12.7 \%(167 / 1315)$ & .000 & 3403 \\
\hline
\end{tabular}

\section{iii) La introducción de variables de control: edad y sexo}

Se introdujeron las variables de control "edad" y "género" para ver si afectaban la relación entre las variables anteriormente consideradas y los actos delictivos.

Las tablas 7 y 8 permiten observar la relación entre la delincuencia y las actividades estructuradas / no estructurada de acuerdo a la variable edad. Esta variable de control se dividió en dos categorías: jóvenes entre 12 y 14 años y aquellos entre 15 y 17 años.

Para los jóvenes de 12 a 14 años, la relación entre la delincuencia y las actividades estructuradas resultaron ser siempre significativas, a excepción de los delitos violentos frecuentes y la venta de drogas. Por ejemplo, entre aquellos que realizan pocas actividades estructuradas, el $6,3 \%$ ya ha cometido delitos contra la propiedad, contra el 3,1\% que dedican un tiempo medio a estas actividades y el $0,8 \%$ de los que pasan mucho tiempo en dichas actividades. Para los jóvenes de 15 a 17 años, las relaciones resultaron ser siempre significativas, por ejemplo el $12,7 \%$ de los jóvenes que practican pocas actividades estructuradas ya han cometido hurto, contra el 7,5\% y el 4,1\% de aquellos que pasan un tiempo medio o alto en estas actividades.

En cuanto a las actividades no estructuradas, la tabla 8 muestra que en el caso de los dos grupos de edad las relaciones son todas significativas; más los jóvenes participan en estas actividades, más se implican en la delincuencia. Por ejemplo, para la categoría de los jóvenes entre 15 y 17 años, el consumo de hachís no es muy frecuente $(1,2 \%)$, entre los que realizan pocas actividades no estructuradas, mientras que es mucho más alto $(9,2 \%$ y $17,4 \%)$ entre los adolescentes que las realizan de manera moderada o a menudo. 
Tabla 7. Relación entre la delincuencia (prevalencia de 12 meses o 4 semanas) y el tiempo dedicado a realizar actividades estructuradas según la edad.

\begin{tabular}{|c|c|c|c|c|c|c|c|c|c|c|}
\hline \multirow[b]{4}{*}{ Delitos } & \multicolumn{10}{|c|}{ Edad } \\
\hline & \multicolumn{5}{|c|}{$12-14$ años } & \multicolumn{5}{|c|}{$15-17$ años } \\
\hline & \multicolumn{3}{|c|}{ Actividades estructuradas } & \multirow[b]{2}{*}{ Sig. } & \multirow[b]{2}{*}{$\mathbf{N}$} & \multicolumn{3}{|c|}{ Actividades estructuradas } & \multirow[b]{2}{*}{ Sig. } & \multirow[b]{2}{*}{$\mathbf{N}$} \\
\hline & poco & suficiente & mucho & & & poco & suficiente & mucho & & \\
\hline $\begin{array}{l}\text { Delitos violentos } \\
\text { frecuentes }\end{array}$ & $\begin{array}{c}16.2 \% \\
(105 / 649)\end{array}$ & $\begin{array}{c}10.0 \% \\
(78 / 782)\end{array}$ & $\begin{array}{c}7.4 \% \\
(38 / 513) \\
\end{array}$ & .000 & 1944 & $\begin{array}{c}20.9 \% \\
(161 / 770) \\
\end{array}$ & $\begin{array}{c}10.5 \% \\
(58 / 553)\end{array}$ & $\begin{array}{c}7.7 \% \\
(21 / 271) \\
\end{array}$ & .000 & 1594 \\
\hline $\begin{array}{l}\text { Delitos violentos } \\
\text { raros }\end{array}$ & $\begin{array}{c}3.2 \% \\
(21 / 650)\end{array}$ & $\begin{array}{c}1.8 \% \\
(14 / 783)\end{array}$ & $\begin{array}{c}1.4 \% \\
(7 / 513)\end{array}$ & .061 & 1946 & $\begin{array}{c}4.3 \% \\
(33 / 744)\end{array}$ & $\begin{array}{c}1.8 \% \\
(10 / 553)\end{array}$ & $\begin{array}{c}0.7 \% \\
(2 / 271)\end{array}$ & .002 & 1598 \\
\hline Vandalismo & $\begin{array}{c}10.1 \% \\
(65 / 642) \\
\end{array}$ & $\begin{array}{c}5.4 \% \\
(42 / 776) \\
\end{array}$ & $\begin{array}{c}5.1 \% \\
(26 / 510) \\
\end{array}$ & .000 & 1928 & $\begin{array}{c}13.1 \% \\
(101 / 773) \\
\end{array}$ & $\begin{array}{c}4.9 \% \\
(27 / 549) \\
\end{array}$ & $\begin{array}{c}3.3 \% \\
(9 / 270) \\
\end{array}$ & .000 & 1592 \\
\hline Hurto & $\begin{array}{c}12.4 \% \\
(80 / 643)\end{array}$ & $\begin{array}{c}8.4 \% \\
(66 / 783) \\
\end{array}$ & $\begin{array}{c}5.3 \% \\
(27 / 511) \\
\end{array}$ & .000 & 1937 & $\begin{array}{c}12.7 \% \\
(98 / 770)\end{array}$ & $\begin{array}{c}7.5 \% \\
(41 / 549) \\
\end{array}$ & $\begin{array}{c}4.1 \% \\
(11 / 270)\end{array}$ & .000 & 1589 \\
\hline $\begin{array}{l}\text { Delitos contra la } \\
\text { propiedad }\end{array}$ & $\begin{array}{c}6.3 \% \\
(41 / 652) \\
\end{array}$ & $\begin{array}{c}3.1 \% \\
(24 / 782) \\
\end{array}$ & $\begin{array}{c}0.8 \% \\
(4 / 513) \\
\end{array}$ & .000 & 1947 & $\begin{array}{c}8.9 \% \\
(69 / 776) \\
\end{array}$ & $\begin{array}{c}4.7 \% \\
(26 / 555) \\
\end{array}$ & $\begin{array}{c}1.5 \% \\
(4 / 271) \\
\end{array}$ & .000 & 1602 \\
\hline Venta de droga & $\begin{array}{c}2.3 \% \\
(15 / 642)\end{array}$ & $\begin{array}{c}1.5 \% \\
(12 / 775)\end{array}$ & $\begin{array}{c}0.8 \% \\
(4 / 512)\end{array}$ & .112 & 1929 & $\begin{array}{c}7.6 \% \\
(58 / 763)\end{array}$ & $\begin{array}{c}1.6 \% \\
(9 / 548)\end{array}$ & $\begin{array}{c}0.7 \% \\
(2 / 271)\end{array}$ & .000 & 1582 \\
\hline Alcohol & $\begin{array}{c}37.9 \% \\
(247 / 651)\end{array}$ & $\begin{array}{c}23.6 \% \\
(185 / 783)\end{array}$ & $\begin{array}{c}19.0 \% \\
(97 / 511)\end{array}$ & .000 & 1945 & $\begin{array}{c}63.5 \% \\
(493 / 776)\end{array}$ & $\begin{array}{c}50.1 \% \\
(278 / 555)\end{array}$ & $\begin{array}{c}31.4 \% \\
(85 / 271)\end{array}$ & .000 & 1602 \\
\hline Hachís & $\begin{array}{c}6.1 \% \\
(39 / 641)\end{array}$ & $\begin{array}{c}3.6 \% \\
(28 / 778)\end{array}$ & $\begin{array}{c}1.8 \% \\
(9 / 512)\end{array}$ & .001 & 1931 & $\begin{array}{c}16.5 \% \\
(127 / 772)\end{array}$ & $\begin{array}{c}7.7 \% \\
(42 / 549)\end{array}$ & $\begin{array}{c}3.4 \% \\
(9 / 265)\end{array}$ & .000 & 1586 \\
\hline
\end{tabular}

Tabla 8. Relación entre la delincuencia (prevalencia de 12 meses o 4 semanas) y el tiempo dedicado a realizar actividades no estructuradas según la edad

\begin{tabular}{|c|c|c|c|c|c|c|c|c|c|c|}
\hline \multirow[b]{4}{*}{ Delitos } & \multicolumn{10}{|c|}{ Edad } \\
\hline & \multicolumn{5}{|c|}{$12-14$ años } & \multicolumn{5}{|c|}{$15-17$ años } \\
\hline & \multicolumn{3}{|c|}{ Actividades no estructuradas } & \multirow[b]{2}{*}{ Sig. } & \multirow[b]{2}{*}{$\mathbf{N}$} & \multicolumn{3}{|c|}{ Actividades no estructuradas } & \multirow[b]{2}{*}{ Sig. } & \multirow[b]{2}{*}{$\mathbf{N}$} \\
\hline & poco & suficiente & mucho & & & poco & suficiente & mucho & & \\
\hline $\begin{array}{l}\text { Delitos violentos } \\
\text { frecuentes }\end{array}$ & $\begin{array}{c}5.9 \% \\
(29 / 493)\end{array}$ & $\begin{array}{c}11.8 \% \\
(88 / 746)\end{array}$ & $\begin{array}{c}15.8 \% \\
(102 / 644)\end{array}$ & .000 & 1883 & $\begin{array}{c}5.7 \% \\
(15 / 265)\end{array}$ & $\begin{array}{c}11.6 \% \\
(69 / 594)\end{array}$ & $\begin{array}{c}21.9 \% \\
(149 / 679)\end{array}$ & .000 & 1538 \\
\hline $\begin{array}{l}\text { Delitos violentos } \\
\text { raros }\end{array}$ & $\begin{array}{c}1.6 \% \\
(8 / 493) \\
\end{array}$ & $\begin{array}{c}0.8 \% \\
(6 / 747) \\
\end{array}$ & $\begin{array}{c}4.4 \% \\
(28 / 643) \\
\end{array}$ & .000 & 1883 & $\begin{array}{c}0.4 \% \\
(1 / 265) \\
\end{array}$ & $\begin{array}{c}1.9 \% \\
(11 / 594 \\
\end{array}$ & $\begin{array}{c}5.1 \% \\
(35 / 682) \\
\end{array}$ & .000 & 1541 \\
\hline Vandalismo & $\begin{array}{c}2.0 \% \\
(10 / 488)\end{array}$ & $\begin{array}{c}4.7 \% \\
(35 / 739)\end{array}$ & $\begin{array}{c}12.8 \% \\
(82 / 641)\end{array}$ & .000 & 1868 & $\begin{array}{c}2.3 \% \\
(6 / 262)\end{array}$ & $\begin{array}{c}7.0 \% \\
(42 / 596)\end{array}$ & $\begin{array}{c}13.1 \% \\
(89 / 678)\end{array}$ & .000 & 1536 \\
\hline Hurto & $\begin{array}{c}5.3 \% \\
(26 / 493)\end{array}$ & $\begin{array}{c}7.4 \% \\
(55 / 743)\end{array}$ & $\begin{array}{c}13.4 \% \\
(86 / 641)\end{array}$ & .000 & 1877 & $\begin{array}{c}2.3 \% \\
(6 / 265)\end{array}$ & $\begin{array}{c}8.6 \% \\
(51 / 590)\end{array}$ & $\begin{array}{c}13.0 \% \\
(88 / 676)\end{array}$ & .000 & 1531 \\
\hline $\begin{array}{l}\text { Delitos contra } \\
\text { la propiedad }\end{array}$ & $\begin{array}{c}1.2 \% \\
(6 / 493)\end{array}$ & $\begin{array}{c}2.9 \% \\
(22 / 747)\end{array}$ & $\begin{array}{c}5.7 \% \\
(37 / 644)\end{array}$ & .000 & 1884 & $\begin{array}{c}0.4 \% \\
(1 / 265)\end{array}$ & $\begin{array}{c}4.2 \% \\
(25 / 595)\end{array}$ & $\begin{array}{c}10.5 \% \\
(72 / 685)\end{array}$ & .000 & 1545 \\
\hline Venta de droga & $\begin{array}{c}0.4 \% \\
(2 / 491)\end{array}$ & $\begin{array}{c}0.9 \% \\
(7 / 743)\end{array}$ & $\begin{array}{c}2.8 \% \\
(18 / 635) \\
\end{array}$ & .001 & 1869 & $\begin{array}{c}0.8 \% \\
(2 / 263)\end{array}$ & $\begin{array}{c}3.9 \% \\
(23 / 592)\end{array}$ & $\begin{array}{c}6.5 \% \\
(44 / 672) \\
\end{array}$ & .000 & 1527 \\
\hline Alcohol & $\begin{array}{c}12.6 \% \\
(62 / 492)\end{array}$ & $\begin{array}{c}25.9 \% \\
(193 / 746)\end{array}$ & $\begin{array}{c}41.1 \% \\
(265 / 645)\end{array}$ & .000 & 1883 & $\begin{array}{c}33.0 \% \\
(87 / 264)\end{array}$ & $\begin{array}{c}54.3 \% \\
(323 / 595)\end{array}$ & $\begin{array}{c}63.5 \% \\
(435 / 685)\end{array}$ & .000 & 1544 \\
\hline Hachís & $\begin{array}{c}1.2 \% \\
(6 / 490)\end{array}$ & $\begin{array}{c}2.6 \% \\
(19 / 744)\end{array}$ & $\begin{array}{c}7.7 \% \\
(49 / 635)\end{array}$ & .000 & 1869 & $\begin{array}{c}1.2 \% \\
(3 / 260)\end{array}$ & $\begin{array}{c}9.2 \% \\
(54 / 590)\end{array}$ & $\begin{array}{c}17.4 \% \\
(118 / 680)\end{array}$ & .000 & 1530 \\
\hline
\end{tabular}


Se ha visto que la introducción de la variable de un control "edad" en el análisis bivariado no alteró significativamente la relación entre las actividades estructuradas/no estructuradas y comportamiento delincuente. De hecho, estas relaciones de nuevo mostraron ser todas significativas, con la excepción de dos $\operatorname{casos}^{11}$, en los cuales el número reducido de jóvenes involucrados pone en duda los resultados obtenidos. Finalmente se observan diferencias entre los jóvenes de 12-14 años y los de 15-17 años de edad, en el grado de implicación en la delincuencia. En particular, las diferencias más significativas, ya sea en el contexto de actividades estructuradas o no estructuradas, se encuentran en las variables "delitos contra la propiedad", "la venta de drogas", "consumo de alcohol" y "hachís". Esto permite suponer que estas conductas desviadas son mucho más frecuentes entre los adolescentes mayores, ya que estos salen con más frecuencia que los más jóvenes. Ellos, de acuerdo con la teoría de las ocasiones, tienen un mayor número de oportunidades para cometer estos actos desviados.

Las tablas 9 y 10 muestran la relación entre delincuencia y las actividades estructuradas/no estructurada en función de la variable de control «sexo».

Nótese que para las chicas la relación entre la delincuencia y las actividades estructuradas son siempre significativas con un p-valor de .000 para todos los comportamiento delictivos, salvo para los delitos violentos raros. De manera comparable, en los varones las relaciones son todas significativas con p-valor de .000 con excepción de los delitos violentos raros y el hurto o robo. Por ejemplo, solamente el 1,6\% de los varones que pasan mucho tiempo realizando actividades estructuradas han ya vendido drogas, contra el $3 \%$ y el $6,9 \%$ de los que consagran un tiempo medio o poco tiempo.

En cuanto a las actividades no estructuradas, la Tabla 10 muestra, una vez más, tanto para las niñas como para los varones, que la relación entre estas actividades y la conducta delictiva son todas significativas. Los P-valores son todos de .000 , con excepción de los delitos violentos raros y la de venta de drogas en los individuos de sexo femenino. Por ejemplo, una minoría de las que realizan pocas actividades no estructuradas $(16,3 \%)$ ha ya consumido alcohol, contra un $34,8 \%$ de las que dedican un tiempo suficiente y el $52 \%$ de las que consagran mucho tiempo.

A manera de conclusión en este punto, se puede decir que la introducción de la variable de control «sexo» en el análisis bivariado no alteró significativamente la rela-

11 Se trata de las relaciones entre venta de droga/ delito violentos frecuentes y actividades estructuradas en los jóvenes de 12 a 14 años. ción entre las actividades estructuradas y no estructuradas / y el comportamiento delincuente, estas relaciones permanecen en efecto, una vez más todas significativas. Sin embargo, se observa una marcada diferencia entre niños y niñas en cuanto a la implicación en la delincuencia y esto para todos los comportamientos delictivos, con la excepción de los hurtos en almacenes y el consumo de alcohol. Estas anomalías pueden explicarse por el hecho de que estos dos tipos de comportamiento, a diferencia de los otros, no son ni violento ni muy estigmatizado, lo que implica que tanto chicos como chicas estén involucrados de una manera similar.

Los resultados del análisis bivariado parecen pues confirmar las hipótesis. En efecto, se constata que las actividades estructuradas reducen globalmente los riesgos de adoptar comportamientos delictivos y contrariamente las actividades no estructuradas aumentan la implicación de los adolescentes en este tipo de comportamiento.

\section{Discusión}

El objetivo de la investigación fue establecer la relación entre las variables independientes y la conducta delictiva. De acuerdo con las hipótesis formuladas, se esperaba que las actividades estructuradas tuvieran un efecto protector contra la delincuencia y las actividades no estructuradas al contrario constituyeran un factor de riesgo. En este aparte se realiza un balance de los resultados y se discutir la validez de las hipótesis. Pero antes de eso, en primer lugar se analiza el papel de las variables indíciales y de control.

La variable «actividades estructuradas» constituye un factor protector contra todos los comportamientos delictivos y se la encuentra en el caso de la mayoría de los comportamientos entre las actividades más predictivos, con la excepción de las relaciones los delitos violentos raros y el vandalismo.

En cuanto a la variable «actividades no estructuradas», ella representa un factor de riesgo para todos los comportamientos delincuentes y se encuentra siempre entre las variables más predictivas, excepto en el caso de la venta de drogas.

Las variables de control han permitido de constatar que los varones están más involucrados que las niñas en todos los tipos de delitos, con excepción de los hurtos en almacenes y el consumo de alcohol. En cambio, la edad no representa un factor de riesgo sino para la mitad de los comportamientos, especialmente con respecto a los delitos contra la propiedad, la venta de drogas, consumo de alcohol y hachís. En fin los jóvenes más supervisados por sus padres tienen menos probabilidades de estar involucrados en cualquier conducta criminal, pero esta variable es a menudo una de los menos predictivas. 
Tabla 9. Relación entre la delincuencia (prevalencia de 12 meses o 4 semanas) y el tiempo dedicado a realizar actividades estructuradas según el sexo

\begin{tabular}{|c|c|c|c|c|c|c|c|c|c|c|}
\hline \multirow[b]{4}{*}{ Delitos } & \multicolumn{10}{|c|}{ Sexo } \\
\hline & \multicolumn{5}{|c|}{ Mujeres } & \multicolumn{5}{|c|}{ Hombres } \\
\hline & \multicolumn{3}{|c|}{ Actividades estructuradas } & \multirow[b]{2}{*}{ Sig. } & \multirow[b]{2}{*}{$\mathbf{N}$} & \multicolumn{3}{|c|}{ Actividades estructuradas } & \multirow[b]{2}{*}{ Sig. } & \multirow[b]{2}{*}{$\mathbf{N}$} \\
\hline & poco & suficiente & mucho & & & poco & suficiente & mucho & & \\
\hline $\begin{array}{l}\text { Delitos violentos } \\
\text { frecuentes }\end{array}$ & $\begin{array}{c}8.5 \% \\
(51 / 603) \\
\end{array}$ & $\begin{array}{c}4.0 \% \\
(28 / 695)\end{array}$ & $\begin{array}{c}1.9 \% \\
(9 / 477)\end{array}$ & .000 & 1775 & $\begin{array}{c}26.4 \% \\
(216 / 817)\end{array}$ & $\begin{array}{c}16.9 \% \\
(108 / 639)\end{array}$ & $\begin{array}{c}16.3 \% \\
(50 / 306)\end{array}$ & .000 & 1762 \\
\hline $\begin{array}{l}\text { Delitos violentos } \\
\text { raros }\end{array}$ & $\begin{array}{c}2.0 \% \\
(12 / 607) \\
\end{array}$ & $\begin{array}{c}0.7 \% \\
(5 / 695) \\
\end{array}$ & $\begin{array}{c}0.6 \% \\
(3 / 478) \\
\end{array}$ & .048 & 1780 & $\begin{array}{c}5.1 \% \\
(42 / 816) \\
\end{array}$ & $\begin{array}{c}2.8 \% \\
(18 / 639) \\
\end{array}$ & $\begin{array}{c}2.3 \% \\
(7 / 307) \\
\end{array}$ & .022 & 1762 \\
\hline Vandalismo & $\begin{array}{c}7.7 \% \\
(47 / 607) \\
\end{array}$ & $\begin{array}{c}3.2 \% \\
(22 / 692) \\
\end{array}$ & $\begin{array}{c}3.0 \% \\
(14 / 474)\end{array}$ & .000 & 1773 & $\begin{array}{c}14.7 \% \\
(119 / 808) \\
\end{array}$ & $\begin{array}{c}7.3 \% \\
(46 / 631) \\
\end{array}$ & $\begin{array}{c}6.9 \% \\
(21 / 305) \\
\end{array}$ & .000 & 1744 \\
\hline Hurto & $\begin{array}{c}14.4 \% \\
(87 / 604)\end{array}$ & $\begin{array}{c}7.5 \% \\
(52 / 694) \\
\end{array}$ & $\begin{array}{c}4.0 \% \\
(19 / 474)\end{array}$ & .000 & 1772 & $\begin{array}{c}11.2 \% \\
(91 / 809)\end{array}$ & $\begin{array}{c}8.6 \% \\
(55 / 636) \\
\end{array}$ & $\begin{array}{c}6.2 \% \\
(19 / 306)\end{array}$ & .026 & 1751 \\
\hline $\begin{array}{l}\text { Delitos contra la } \\
\text { propiedad }\end{array}$ & $\begin{array}{c}4.6 \% \\
(28 / 609) \\
\end{array}$ & $\begin{array}{c}1.4 \% \\
(10 / 696) \\
\end{array}$ & $\begin{array}{c}0.4 \% \\
(2 / 477)\end{array}$ & .000 & 1782 & $\begin{array}{c}10.0 \% \\
(82 / 818)\end{array}$ & $\begin{array}{c}6.3 \% \\
(40 / 640) \\
\end{array}$ & $\begin{array}{c}2.0 \% \\
(6 / 305) \\
\end{array}$ & .000 & 1764 \\
\hline Venta de droga & $\begin{array}{c}2.9 \% \\
(17 / 596)\end{array}$ & $\begin{array}{c}0.3 \% \\
(2 / 687)\end{array}$ & $\begin{array}{c}0.2 \% \\
(1 / 477)\end{array}$ & .000 & 1760 & $\begin{array}{c}6.9 \% \\
(56 / 809) \\
\end{array}$ & $\begin{array}{c}3.0 \% \\
(19 / 634)\end{array}$ & $\begin{array}{c}1.6 \% \\
(5 / 305)\end{array}$ & .000 & 1748 \\
\hline Alcohol & $\begin{array}{c}54.6 \% \\
(334 / 612)\end{array}$ & $\begin{array}{c}30.0 \% \\
(209 / 696)\end{array}$ & $\begin{array}{c}21.2 \% \\
(101 / 476)\end{array}$ & .000 & 1784 & $\begin{array}{c}50.1 \% \\
(408 / 815)\end{array}$ & $\begin{array}{c}39.6 \% \\
(254 / 641)\end{array}$ & $\begin{array}{c}26.1 \% \\
(80 / 306)\end{array}$ & .000 & 1762 \\
\hline Hachís & $\begin{array}{c}8.6 \% \\
(52 / 605)\end{array}$ & $\begin{array}{c}3.7 \% \\
(26 / 695)\end{array}$ & $\begin{array}{c}2.3 \% \\
(11 / 473)\end{array}$ & .000 & 1773 & $\begin{array}{c}14.1 \% \\
(114 / 807)\end{array}$ & $\begin{array}{c}7.0 \% \\
(44 / 630)\end{array}$ & $\begin{array}{c}2.0 \% \\
(6 / 302)\end{array}$ & .000 & 1739 \\
\hline
\end{tabular}

Tabla 10. Relación entre la delincuencia (prevalencia de 12 meses o 4 semanas) y el tiempo dedicado a realizar actividades estructuradas según el sexo

\begin{tabular}{|c|c|c|c|c|c|c|c|c|c|c|}
\hline \multirow{4}{*}{ Delitos } & \multicolumn{10}{|c|}{ Sexo } \\
\hline & \multicolumn{5}{|c|}{ Mujeres } & \multicolumn{5}{|c|}{ varones } \\
\hline & \multicolumn{3}{|c|}{ Actividades no estructuradas } & \multirow[b]{2}{*}{ Sig. } & \multirow[b]{2}{*}{$\mathbf{N}$} & \multicolumn{3}{|c|}{ Actividades no estructuradas } & \multirow[b]{2}{*}{ Sig. } & \multirow[b]{2}{*}{$\mathbf{N}$} \\
\hline & poco & suficiente & mucho & & & poco & suficiente & mucho & & \\
\hline $\begin{array}{l}\text { Delitos violentos } \\
\text { frecuentes }\end{array}$ & $\begin{array}{c}1.2 \% \\
(5 / 417) \\
\end{array}$ & $\begin{array}{c}3.0 \% \\
(20 / 656) \\
\end{array}$ & $\begin{array}{c}9.5 \% \\
(62 / 656) \\
\end{array}$ & .000 & 1729 & $\begin{array}{c}11.4 \% \\
(39 / 341) \\
\end{array}$ & $\begin{array}{c}19.9 \% \\
(136 / 684) \\
\end{array}$ & $\begin{array}{c}28.6 \% \\
(190 / 665) \\
\end{array}$ & .000 & 1690 \\
\hline $\begin{array}{l}\text { Delitos violentos } \\
\text { raros }\end{array}$ & $\begin{array}{c}0.5 \% \\
(2 / 418)\end{array}$ & $\begin{array}{c}0.6 \% \\
(4 / 659)\end{array}$ & $\begin{array}{c}2.3 \% \\
(15 / 657) \\
\end{array}$ & .006 & 1734 & $\begin{array}{c}2.1 \% \\
(7 / 340)\end{array}$ & $\begin{array}{c}2.0 \% \\
(14 / 685) \\
\end{array}$ & $\begin{array}{c}7.2 \% \\
(48 / 664) \\
\end{array}$ & .000 & 1689 \\
\hline Vandalismo & $\begin{array}{c}1.0 \% \\
(4 / 418)\end{array}$ & $\begin{array}{c}2.3 \% \\
(15 / 655)\end{array}$ & $\begin{array}{c}9.7 \% \\
(64 / 657)\end{array}$ & .000 & 1730 & $\begin{array}{c}3.6 \% \\
(12 / 332)\end{array}$ & $\begin{array}{c}9.0 \% \\
(61 / 681)\end{array}$ & $\begin{array}{c}16.3 \% \\
(107 / 658)\end{array}$ & .000 & 1671 \\
\hline $\begin{array}{l}\text { Hurto en } \\
\text { almacenes }\end{array}$ & $\begin{array}{c}4.3 \% \\
(18 / 417)\end{array}$ & $\begin{array}{c}5.7 \% \\
(37 / 654)\end{array}$ & $\begin{array}{c}14.9 \% \\
(98 / 656)\end{array}$ & .000 & 1727 & $\begin{array}{c}3.8 \% \\
(13 / 340)\end{array}$ & $\begin{array}{c}10.2 \% \\
(69 / 679)\end{array}$ & $\begin{array}{c}11.7 \% \\
(77 / 658)\end{array}$ & .000 & 1677 \\
\hline $\begin{array}{l}\text { Delitos contra } \\
\text { la propiedad }\end{array}$ & $\begin{array}{c}0 \% \\
(0 / 418)\end{array}$ & $\begin{array}{c}1.5 \% \\
(10 / 660)\end{array}$ & $\begin{array}{c}4.6 \% \\
(30 / 659)\end{array}$ & .000 & 1737 & $\begin{array}{c}2.1 \% \\
(7 / 340)\end{array}$ & $\begin{array}{c}5.5 \% \\
(38 / 685)\end{array}$ & $\begin{array}{c}12.0 \% \\
(80 / 666)\end{array}$ & .000 & 1691 \\
\hline Venta de droga & $\begin{array}{c}0 \% \\
(0 / 417)\end{array}$ & $\begin{array}{c}1.1 \% \\
(7 / 653)\end{array}$ & $\begin{array}{c}2.0 \% \\
(13 / 649)\end{array}$ & .011 & 1719 & $\begin{array}{c}1.2 \% \\
(4 / 338)\end{array}$ & $\begin{array}{c}3.4 \% \\
(23 / 684)\end{array}$ & $\begin{array}{c}7.5 \% \\
(49 / 654)\end{array}$ & .000 & 1676 \\
\hline Alcohol & $\begin{array}{c}16.3 \% \\
(68 / 416)\end{array}$ & $\begin{array}{c}34.8 \% \\
(229 / 658)\end{array}$ & $\begin{array}{c}52.0 \% \\
(345 / 663)\end{array}$ & .000 & 1737 & $\begin{array}{c}23.8 \% \\
(81 / 340)\end{array}$ & $\begin{array}{c}42.1 \% \\
(288 / 684)\end{array}$ & $\begin{array}{c}53.4 \% \\
(354 / 663)\end{array}$ & .000 & 1687 \\
\hline Hachís & $\begin{array}{c}1.0 \% \\
(4 / 414)\end{array}$ & $\begin{array}{c}3.6 \% \\
(24 / 658)\end{array}$ & $\begin{array}{c}9.6 \% \\
(63 / 659) \\
\end{array}$ & .000 & 1731 & $\begin{array}{c}1.5 \% \\
(5 / 336)\end{array}$ & $\begin{array}{c}7.2 \% \\
(49 / 678)\end{array}$ & $\begin{array}{c}15.9 \% \\
(104 / 653)\end{array}$ & .000 & 1667 \\
\hline
\end{tabular}


Volviendo a las hipótesis, se puede decir que las actividades estructuradas reducen el grado de participación en la delincuencia, pues más el joven realice este tipo de actividades de ocio, corre menos arriesgo de implicarse en la delincuencia, las actividades no estructuradas representan en cambio un factor de riesgo para los adolescentes. En efecto, estas actividades sin estructura o supervisión de los adultos resultaron ser caldo de cultivo para la delincuencia.

Dicho esto, no se aboga obviamente por la eliminación total de las actividades recreativas no estructuradas. Se está muy consciente de que si por un lado las actividades no estructuradas representan un factor de riesgo para la delincuencia, por el otro lado contienen un importante valor educativo para el individuo. De hecho, esas experiencias no planificadas y no organizadas contribuyen al desarrollo de la autonomía y la identidad de los adolescentes (Caldwell y Darling, 1999; Silbereisen y Noack Eyferth, 1986), y es precisamente por estas razones que en lugar de eliminarlas, se debe tratar de limitar el impacto adverso, alternándolas con otras más estructuradas, para que el joven tenga la oportunidad de conocer los aspectos beneficiosos propios de los diferentes tipos de recreación.

\section{Conclusión}

En general, la investigación ha encontrado que el tipo de entretenimiento, ya sea a través de actividades estructurada o no estructurada, es un factor importante que debe tenerse en cuenta al abordar el tema de la delincuencia juvenil. De hecho, en el estudio las variables independientes resultaron predictiva incluso después de haber verificado la influencia de ciertas variables de control que se suponen ser de los factores más indicativos de la delincuencia. Los resultados del estudio son alentadores, y plantea la necesidad de realizar investigaciones más específicas sobre la relación entre el ocio o manejo del tiempo libre y la delincuencia juvenil. Es fundamental tener en cuenta una gama más amplia de actividades realizadas, si se quiere revelar el peso de esta variable en el comportamiento de los adolescentes. En particular, sería interesante incluir en el análisis actividades estructuradas realizadas con el grupo de pares (en el seno de una asociación de carácter cultural, deportiva, política, religiosa o de otro tipo) con el fin de comprender si es la presencia de los amigos la que tienen un efecto negativo o si es al contrario al hecho de que la actividad sea estructura el factor determinante en la tendencia de la criminalidad en el individuo. En este sentido, un estudio de Mahoney y Stattin (2000) encontró que la participación en actividades estructuradas con sus compañeros (actividades extracurriculares dentro de la escuela o de la comunidad) reduce el riesgo de actos delictivos y la participación en actividades no estructuradas se asocia con aumento de la conducta antisocial.

Más allá de los aspectos ligados a la criminología, el desarrollo de actividades estructuradas y con fines educativos es un desafío que debe interesar a toda la sociedad. Este tipo de actividad constituye un elemento clave para enseñar a los jóvenes a convertirse en adultos responsables, en el respeto por los demás y las normas. Por lo tanto, como se indica en el Informe de la ONU sobre Juventud (2003), es necesario proporcionarles oportunidades para el desarrollo constructivo, dándoles los medios para participar activamente en la vida comunitaria.

\section{Referencias}

Aebi, M. F. (2006). Comment mesurer la délinquance? Paris: Armand Colin.

Aebi, M. F. (2009). Enquêtes de délinquance autoreportée en Europe. Paris: Brochure du forum européen pour la sécurité urbaine.

Agnew, R., \& Petersen, D. M. (1989). Leisure and delinquency. Social problems, 36, 332-350.

Akers, R. L., Krohn, M.D., Lanza-Kaduce, L., Radosevich, M. (1979). Social learning and deviant behavior: A specific test of a general. American Sociological Review, 44(4), 635-655.

Bandura, A. (1980). L'apprentissage social ( trad. J-A. Rondal). Bruxelles: Mardaga (éd. originale, 1976). 
Barnes, G. M., Hoffman , J. H., Welte , J. W., Farrell , M. P., \& Dintcheff , B. A. ( 2006). Adolescents' time use: Effects on substance use, delinquency, and sexual activity. Journal of Youth and Adolescence , 36, 697-710.

Caldwell, L. L., Darling, N. (1999). Leisure context, parental control, and resistance to peer pressure as predictors of adolescent partying and substance use: an ecological perspective. Journal of Leisure Research, 31, 57-77.

Cohen, L. E., \& Felson, M. (1979). Social change and crime rate trends. A routine activities approach. American Sociological Review, 44(4), 588-608.

Commission fédérale pour l'enfance et la jeunesse. (2005). ...et puis la journée est finie! Temps libre, espaces libres et mouvement pour les enfants et les jeunes. Consultable à l'adresse suivante : http:/ / www.ekkj.admin.ch/c_data/f_05_rap_ Freiraum.pdf.

Elliott, D. S., \& Voss, H. L. (1974). Delinquency and Dropout. Lexington, MA : Heath (d'après Hayne \& Osgood, 2005).

Elliott, D.S., \& Menard, S.(1996). Delinquent friends and delinquent behavior: Temporal and developmental patterns. In D. J. Hawkins (ed.), Delinquency and Crime: Current theories (pp. 28-67). New York: Cambridge University Press.

Glueck, S., Glueck, E. (1950). Unraveling juvenile delinquency. New York: Commonwealth Fund (d'après Killias, 2001).

Hayne, D. L. \& Osgood, D. W. (2005) . Reconsidering peers and delinquency: How do peers matter? Social Forces, 84(2), 1109-1130.

Hindelang, M. J. (1973). Causes of delinquency. A partial replication and extension. Social Problems, 20(4), 471-487.

Hindelang, M. J., Gottfredson, M. R., \& Garofalo, J. (1978). Victims of personal crime: An empirical foundation for a theory of personal victimization. Cambridge, MA: Ballinger (d'après Killias, 2001).

Hirschi, T. (1971). Causes of delinquency. Berkeley, CA: University of California Press (version originale, 1969).

Junger-Tas, J., Block, R.L. (1988). Juvenile delinquency in the Netherlands. Amstelveen, AM : Kugler.

Killias, M. (2001). Précis de criminologie. Berne: Staempfli.

Killias M., Aebi, M. F., Herrmann, L., Lucia, S. (2009). Switzerland. In D. Enzmann, B. Gruszcynska, I. Haen- Marshal, J. Junger-Tas, M. Killias, M. Steketee (Eds.), Juvenile delinquency in Europe and beyond: An international perspective on key issues and causes(pp.7996).Dordrecht[etc.]:Spring

LaGrange, R. L., White, H. R. (1985). Age differences in delinquency: A test of theory. Criminology, 23(1), 19-45.

Larson, R., Verma, S. (1999). How children and adolescent spend time across the world: Work, play and developmental opportunities. Psychological Bulletin, 125(6), 701-736.

Mahoney, J .L., Stattin, H. (2000). Leisure activities and adolescent antisocial behavior: The role of structure and social context. Journal of Adolescence, 23, 113-127.

Opp, K. D. (1974). Abweichendes verhalten und gesellschaftsstruktur. Darmstadt, Neuwied ( d'après Killias, 2001).

Osgood, D. W., Wilson, J. K., O'Malley, P. M., Bachman, J. G., Johnston, L.D. (1996). Routine activities and individual behavior. American Sociological Review, 61(4), 635-655.

Rey-Debove, J., Rey, A. (1993). Le Nouveau Petit Robert. Paris : Éditions Le Robert.

Silbereisen, R. K.., Noack, P., Eyferth, K. (1986). Place for development: Adolescents, leisure settings, and developmental tasks. In R.K. Silbereisen, K. Eyferth, G. Rudlinger (Eds.), Development as action in context: Problem behavior and normal youth development (pp. 87-107). New York: Springer-Verlag.

Sutherland, E. H., Cressey D. R. (1966). Principes de criminologie. Version française établie sur le texte de la sixième édition de Principles of Criminology. Paris : Cujas (version originale, 1947).

Svensson, R., Pauwels, L. (2008). Is a risky lifestyle always "risky"? The interaction between individual propensity and lifestyle risk in adolescent offending. Crime and Delinquency, 20(10), 1-19.

Title, C. R., Burkle, M.J., Jackson, E.F., (1986). Modeling Sutherland's theory of differential association. Toward an empirical classification. Social Forces, 65(2), 405-432. 
United Nations. (2003). World youth report. Consultable à l'adresse suivante: http:/ /www.un.org/esa/socdev/unyin/ documents/ch08.pdf.

Villettaz P. (2009). Documentation du cours de méthodes d'analyse statistique. Lausanne : Master en criminologie ICDP.

Warr, M. (1993). Parents, Peers, and Delinquency. Social Forces, 72(1), 247-264.

Wikström, P.-O. H. (2004). Crime as alternative: Towards a cross-level situational action theory of crime causation. In J. McCord (Ed.), Beyond empiricism: Institutions and intentions in the study of crime (pp. 1-37). New Brunswick, NJ: Transaction.

Wikström, P.-0. H. (2008). Why are English youths more violent than Swedish youths? A comparative study of the role of crime propensity, lifestyles and their interaction in two cities. European Journal of Criminology, 5(3), 309-330.

Wong S. K. (2005). The effects of adolescent activities on delinquency: A differential involvement approach. Journal of Youth and Adolescence, 34(4), 321-333. 